\title{
Recent Trends Toward Fault Tolerance Techniques in MANET
}

\author{
Kulwinder Kaur \\ Computer Science Department \\ Guru Nank Dev University \\ Amritsar, Punjab, India
}

\author{
Kamaljit Kaur \\ Computer Science Department \\ Guru Nank Dev University \\ Amritsar, Punjab, India
}

\begin{abstract}
Mobile ad hoc networks (MANETs) have emerged like a key technology with regard to next-generation wireless networking. MANETs usually are going through rapid progress and also inspiring quite a few purposes. Even so, a lot of complex issues are still dealing with the particular deployment on this technological innovation. On the other hand, adversarial conditions are standard in MANET environments, and there are misbehaving nodes that decay the overall performance.MANETs should be fault tolerant to recover even after a failure occurs. This paper has focused on the significance of the fault tolerant routing protocols and what are the various challenges for fault tolerant MANETs.In this paper, a review on issues in fault tolerance is presented. This review paper has presented various fault tolerance techniques to improve failures in network.
\end{abstract}

Keywords: MANET, Fault Tolerance

\section{INTRODUCTION}

MANET is a kind of wireless ad hoc network. It is a selfconfiguring network of mobile routers connected by wireless links with no access point.[23]Every mobile device in a network is independent. The mobile devices are free to move randomly and establish themselves haphazardly. In other words, ad hoc network do not rely on any fixed infrastructure (i.e. the mobile ad hoc network is infrastructure less wireless network. The Communication in MANET is take place by using multi-hop paths. Nodes in the MANET share the wireless medium and the topology of the network changes unpredictably and vigorously. In MANET, breaking of communication link is very frequent, as nodes are free to move to anywhere. The density of nodes and the number of nodes are depends on the applications in which we are using MANET.

Mobile ad-hoc networks can work in an individual fashion or may be joined to a larger network including the Internet. Mobile ad-hoc networks can turn the vision of getting connected "anyplace and at any time" into reality. Typical application examples add a disaster recovery or a military operation.

Fault-Tolerance is an important to build a reliable mobile ad hoc network. Various kind of faults may arise in mobile network like link failure, node failure, misbehaving nodes, network failure, power and energy consumption so on. Fault tolerance in wireless networks is a challenge not only because of the medium of transmission but also due to the nature of networking device interface. Fault tolerance is applicable to networks that have a greater chance of failure and naturally wireless networks, especially wireless Ad-hoc networks, fall conveniently into this category. Indeed fault tolerance in wireless networks brings with it several factors that make it a challenge

This paper is organized as follows: Section 2 presents growth of MANET. Different characteristic is discussed in Section 3. Section 4 present the review on fault tolerance in Manet Section 5 explore issues and challenges in fault tolerance in Section 6.Finally,analysis of different techniques in fault tolerance.

\section{EVOLUTION OF MANET}

Development involving MANET is [22]:

- In 1970, Normanl Abramson and his fellow researchersat the University of Hawaii invented ALOHAnet.

- In 1972 DARPA Packet Radio Network (PRNet).

- In 1980 Survivable Radio Networks (SURAN).

- During 1980 emergence of Internet Emerging Task Force (IETF), termed the mobile ad hoc networking group.

- In 1994 emergence of Bluetooth by Ericsson.

\section{CHARACTERISTICS OF MANET}

MANET has following characteristics :

1) Scattered operation: specific functions like routing ,security etc. are scattered among nodes from different group[.23]

2) Multi step routing: packet ought to be sent through several transitional nodes

3) Self-sufficient terminal: each mobile node is selfsufficient node, work as both a host and a router.

4) Dynamic topology: the network topology may change so nodes directing among themselves making their own network.

5) Light-weight terminals: nodes are portable with less CPU capacity, low power storage and small memory size.

6) Common Physical Medium: it offers appropriate equipment and satisfactory assets so access to channel cannot restricted.

7) Symmetric environment- Although nodes with similar responsibilities work as a router or host so it structures totally symmetric environment 
8) Absence of Infrastructure- Ad-hoc networks are supposed to operate independently of any fixed infrastructure.

\section{FAULT TOLERANCE IN MANET}

Most existing designs of ad hoc networks are depend on the presumption associated with non-adversarial surroundings i.e. each node in the network are cooperative and well behaved. However, in adversarial environment, misbehaving nodes always exist, and may significantly degrade the routing performance.

The fault tolerant strategy is utilized in quite possibly prevent the malfunctioning node will have an effect on the entire activity of the network. Fault tolerance is used to enhance system reliability. It may be of different types as follows:[27]

a. Fault tolerance in Node Failures

b. Fault tolerance in Link failure and Network Failure

c. Fault tolerance in Transmission Power and Energy

d. Fault tolerance using check-pointing, message logging, reducing overload etc.

Because of node flexibility, the topology of the network can alter frequently; nodes can go far away from the transmission range. Thus, there could possibly be an opportunity of node failure or link failure and node have to consume more energy in order to exchange the packets from source to desired destination. The overall performance of the routing will be reduced due to failures. Node failure takes place whenever deficiency of power, it leads to path failure in the network.

The fault-prone nodes in a mobile ad hoc network (MANET) decrease the functionality of any routing protocol. Making use of greedy routing mechanisms in which every time go to one path, might result in important data losses, when there is a failure of this route in a fault prone environment. However, utilizing all of the available routes will lead to an unwanted amount of overhead on the network. Developing an effective as well as efficient fault-tolerant routing protocol is inherently complicated, because the problem is NP-complete as result the unavailability of exact path information in adversarial environments.

\section{FAULT TOLERANCE ISSUES 5.1 Energy efficient}

V. Jayalakshmi et al (2012) [9] propose an energy efficient multipath fault tolerant routing protocol to improve the reliability of data routing and to improve route stability in mobile ad hoc networks. The proposed RFTA is a multi objective routing protocol that meets diverse application requirements by considering the changing conditions of the network. Compared with some representative existing stable and source -based routing protocols such as SMR, SMS.There has been a recognizable improvement in the packet delivery ratio and also in the decline of end-to-end delay contrasting to different protocols.

\subsection{Host auto-configuration}

M. Nazeeruddin et al (2005) [26] Host auto-configuration of mobile hosts is a key issue in the mobile ad hoc networks (MANETs) as hosts cannot participate in unicast routing without unique addresses. A distributed agent based Dynamic Host Auto configuration Protocol for MANETs (DHAPM) is proposed. In this approach, every address agent has a disjoint set of IP addresses which it can assign to the new node without consulting any other address agents in the network. It also has the ability to handle node failures and message losses

\subsection{Location Management}

RoieMelamed et al (2008) [29] present a fault-tolerant and efficient position-based routing protocol for large MANETs called Octopus .Fault-tolerance is accomplish by using redundancy, i.e., keeping the position of each node at various nodes, and also by maintaining often restored soft state.

Karim khazaei et al (2009) [35] present a novel schema to perform fault tolerant location management named FTLM which is based on nodes disconnection. Using location management scheme, every origin node inside the network trusts a smaller subset associated with nodes that are location servers, and change them with its new geographic location. Fault tolerance in our strategy attained through redundancy within location servers that store node's positions. FTLM is more scalable as compare to Octopus and plus some other location management methods.

\subsection{Overheads}

Olufemi Adeluyi et al (2012) [34] proposed a new routing algorithm for MANETs inspired by nature- Spiral Millipedeinspired Routing Algorithm (SMiRA). It is designed as resource light techniques that minimize routing overhead as well as enhances the degree of tolerance to routing faults, among other things. It was compared to a standard MANET routing protocol called AODV and the result shows significant improvement in the following areas: Routing overhead, Fault Recovery Latency .

Misra et al (2009) [3] The fault-prone nodes, employing all the accessible paths which produce an unwanted amount of overhead on the system. .To handle the issue of effective fault-tolerant routing, present a fault tolerant routing algorithm (FTAR), using concepts of how swarms of natural ants work. The algorithm is break into different phases specifically initialization, path selection, pheromone deposition, confidence calculation, evaporation and negative reinforcement. FTAR better than leading fault-tolerant MANET routing protocol at present, based on the amount of routing overhead.

\subsection{Traffic splitting}

Kiran K et al (2014) [36] discussed fault tolerance in a multi-radio network. Fault tolerance can be realized while using the Beehive routing algorithm. The multi-radio nodes are created making use of WiMAX and Wi-Fi. The paper talks about fault tolerance that used on multi radio nodes which use traffic splitting in the transmission of data. A Method is projected to handle unsystematic faults in hardware radios through using traffic splitting and uniting it with the BeeHive routing algorithm .Fault tolerance allows uninterrupted data transmission and fault recovery mechanisms.

\subsection{Security}

Wanlong et al (2008) [37] In case there are node or network baulks within system, correlative mobile agent's implement will be avoided. This paper reveals failure-tolerance of mobile mechanism uniting secure authentication technique. It assures that the mobile agent can be appropriately sent and can prevent the baleful node juggle or the eliminate agent, and minimizes the time cost of realizing failure-tolerance. 


\section{CHALLENGES}

\subsection{Perfect algorithm to handle all issues} at same time

V. Jayalakshmi (2012) [25] et al. has explored that the major issues in MANETs like routing ,overheads, QOS ,security and load balance which is not solve because perfect algorithm is not available. Because there exist no universal technique which can handle all these issues at same time.

\subsection{Early detection of node crashes}

M. Nazeeruddin et al.(2012)[26] unsuccessful in extensive simulation of the proposed protocol and other host auto configuration protocols which is needed to effectively compare and contrast protocol performance in different real time scenarios. In addition, scalability, security \& overhead minimization of host auto-configuration protocols and to interact with the routing protocols for the early detection of node crashes there by saving the network resources will be addressed.

\subsection{Computation complexity and Energy overhead}

Adeluyi and Lee (2012) [34] has shown that computation complexity and energy overhead are major limitation in manet.

\subsection{Automatic assignment of split coefficients}

Kiran K et al. (2014) [36] summarize that focus on selforganizing networks that handle with automatic assignment of split coefficients for splitting data traffic.

\subsection{Test-beds to check actual outcomes}

SudipMisra et al. (2009) [3] revealed the following challenges as future direction (a)work with some other mobility models,(b) employ networks which have larger number of nodes along with different the network density (c) create test-beds for paying attention to perhaps outcomes stay the same with regards to actual network environments.

\subsection{Energy efficiency}

Parul et al. (2014) [12] explore that the work can be altered by maintaining energy efficiency of the nodes along with factors like Overhead and Packets delivered.

TABLE 1: Comparison of Different Techniques According to Their Characteristics

\begin{tabular}{|l|l|l|l|l|l|l|l|l|}
\hline Technique & $\begin{array}{l}\text { Node } \\
\text { failure }\end{array}$ & $\begin{array}{l}\text { Link or } \\
\text { Network } \\
\text { failure }\end{array}$ & $\begin{array}{l}\text { Check } \\
\text { Pointing }\end{array}$ & $\begin{array}{l}\text { Reduce } \\
\text { Routing } \\
\text { overhead }\end{array}$ & $\begin{array}{l}\text { Message } \\
\text { logging }\end{array}$ & $\begin{array}{l}\text { Centralized } \\
\text { Or } \\
\text { Decentralized }\end{array}$ & Agents & Location \\
\hline $\begin{array}{l}\text { Fault Tolerant Routing } \\
\text { Algorithm } \\
\text { (FTRA) } \\
\text { (2009) }\end{array}$ & $\checkmark$ & $\times$ & $\times$ & $\checkmark$ & $\times$ & $\times$ & Management \\
\hline $\begin{array}{l}\text { Fault-Tolerance Cluster } \\
\text { Head Based Routing } \\
\text { Protocol } \\
\text { (FTCH) } \\
\text { (2008) }\end{array}$ & $\checkmark$ & $\times$ & $\times$ & $\checkmark$ & $\times$ & $\times$ & $\begin{array}{l}\text { Geographic } \\
\text { location }\end{array}$ \\
\hline $\begin{array}{l}\text { Fault-Tolerant 1- } \\
\text { Spanner }\end{array}$ & $\checkmark$ & $\times$ & $\times$ & $\times$ & $\times$ & $\times$ & clustering \\
\hline $\begin{array}{l}\text { Modified Cluster-based } \\
\text { QOS routing algorithm }\end{array}$ & $\checkmark$ & $\times$ & $\times$ & $\times$ & $\times$ & $\times$ & $\times$ & Multiple path \\
\hline $\begin{array}{l}\text { Learning - based weak } \\
\text { estimation method }\end{array}$ & $\checkmark$ & $\times$ & $\times$ & $\checkmark$ & $\times$ & $\times$ & $\times$ & clustering \\
\hline $\begin{array}{l}\text { Learning Automata } \\
\text { Based Fault-Tolerant } \\
\text { Routing Algorithm } \\
\text { (LAFTRA) }\end{array}$ & $\checkmark$ & $\times$ & $\times$ & $\checkmark$ & $\times$ & $\times$ & $\times$ & $\times$ \\
\hline $\begin{array}{l}\text { End-to-End estimation } \\
\text { Fault Tolerant Routing } \\
\text { Algorithm (E2FT) }\end{array}$ & $\checkmark$ & $\times$ & $\times$ & $\checkmark$ & $\times$ & centralized & $\times$ & $\begin{array}{l}\text { Path } \\
\text { estimation } \\
\text { and path } \\
\text { selection are } \\
\text { the two } \\
\text { process }\end{array}$ \\
\hline
\end{tabular}




\begin{tabular}{|c|c|c|c|c|c|c|c|c|}
\hline & & & & & & & & $\begin{array}{l}\text { which is used } \\
\text { to find } \\
\text { multiple path }\end{array}$ \\
\hline $\begin{array}{l}\text { Multipath Fault Tolerant } \\
\text { Routing } \\
\text { Protocol [2012] }\end{array}$ & $\checkmark$ & $x$ & $x$ & $x$ & $x$ & $x$ & $x$ & $\begin{array}{l}\text { Local backup } \\
\text { path }\end{array}$ \\
\hline $\begin{array}{l}\text { Octopus a fault-tolerant } \\
\text { and efficient position- } \\
\text { based routing protocol } \\
{[2008]}\end{array}$ & $x$ & $\checkmark$ & $x$ & $\checkmark$ & $\checkmark$ & $x$ & $x$ & $\begin{array}{l}\text { Store position } \\
\text { of node } \\
\text { at different } \\
\text { node }\end{array}$ \\
\hline $\begin{array}{l}\text { Fault Tolerant } \\
\text { Distributed agent based } \\
\text { dynamic host auto- } \\
\text { configuration protocol } \\
\text { [2012] }\end{array}$ & $\checkmark$ & $x$ & $x$ & $x$ & $\checkmark$ & centralized & $\begin{array}{l}\text { Address } \\
\text { Agent }\end{array}$ & $\begin{array}{l}\text { Distributed } \\
\text { address } \\
\text { allocation } \\
\text { table }\end{array}$ \\
\hline $\begin{array}{l}\text { New fault tolerant } \\
\text { routing protocol extends } \\
\text { of DSR protocol [2011] }\end{array}$ & $x$ & $\checkmark$ & $x$ & $\checkmark$ & $\checkmark$ & $x$ & $x$ & $\begin{array}{l}\text { At least two } \\
\text { paths are } \\
\text { select }\end{array}$ \\
\hline $\begin{array}{l}\text { Self-eliminating Fault- } \\
\text { tolerant based Un- } \\
\text { interrupted reliable } \\
\text { Service switching } \\
\text { mobile Protocol } \\
\text { (SFUSP) }\end{array}$ & $x$ & $\checkmark$ & $x$ & $x$ & $x$ & $x$ & $x$ & $\begin{array}{l}\text { clustering } \\
\text { and } \\
\text { self- } \\
\text { elimination }\end{array}$ \\
\hline $\begin{array}{l}\text { Spiral Millipede- } \\
\text { inspired Routing } \\
\text { Algorithm (SMiRA) } \\
{[2012]}\end{array}$ & $x$ & $\checkmark$ & $x$ & $x$ & $x$ & $x$ & $x$ & $\begin{array}{l}\text { relative } \\
\text { physical } \\
\text { location }\end{array}$ \\
\hline $\begin{array}{l}\text { Mutual Eclusion } \\
\text { (MUTEX) algorithm } \\
\text { [2008] }\end{array}$ & $x$ & $\checkmark$ & $x$ & $x$ & $x$ & $x$ & $x$ & $\begin{array}{l}\text { time out } \\
\text { based method }\end{array}$ \\
\hline $\begin{array}{l}\text { Trusted Fault Tolerant } \\
\text { (TFT) }\end{array}$ & $x$ & $\checkmark$ & $x$ & $x$ & $x$ & $x$ & $x$ & $\begin{array}{l}\text { Location } \\
\text { Aided } \\
\text { Routing } \\
\text { (LAR) }\end{array}$ \\
\hline $\begin{array}{l}\text { Fault-tolerant Local } \\
\text { Spanning Subgraph } \\
\text { algorithm } \\
\text { (FLSS) }\end{array}$ & $x$ & $x$ & $x$ & $x$ & $x$ & centralized & $x$ & $\begin{array}{l}\text { k-vertex } \\
\text { connectivity }\end{array}$ \\
\hline $\begin{array}{l}\text { Adaptive Fault Tolerant } \\
\text { Replication (AFTR) } \\
\text { routing protocol }\end{array}$ & $x$ & $x$ & $\checkmark$ & $x$ & $x$ & $x$ & $x$ & $x$ \\
\hline $\begin{array}{l}\text { NxN matrix and K-FT } \\
\text { topology }\end{array}$ & $x$ & $x$ & $\checkmark$ & $x$ & $x$ & $x$ & $x$ & $x$ \\
\hline $\begin{array}{l}\text { Matrix Matrix } \\
\text { Multiplication algorithm }\end{array}$ & $x$ & $x$ & $\checkmark$ & $x$ & $x$ & $x$ & $x$ & $\begin{array}{l}\text { Checksum } \\
\text { information }\end{array}$ \\
\hline $\begin{array}{l}\text { Dynamic -Distributed } \\
\text { Self-Diagnosis Protocol } \\
\text { (DSDP) } \\
\text { (2008) }\end{array}$ & $\checkmark$ & $x$ & $\checkmark$ & $x$ & $x$ & $x$ & $x$ & $x$ \\
\hline $\begin{array}{l}\text { Fault Tolerant Location } \\
\text { Management } \\
\text { (FTLM) } \\
\text { 2009) }\end{array}$ & $\checkmark$ & $x$ & $x$ & $\begin{array}{l}\text { Packet } \\
\text { overhead }\end{array}$ & $\checkmark$ & $x$ & $x$ & $\begin{array}{l}\text { Geographic } \\
\text { location }\end{array}$ \\
\hline
\end{tabular}




\section{LIMITATIONS OF EARLIER WORK}

1. The effect of the node failures has also been neglected in the most of the existing research

2. Most of the existing techniques are based on the concept of protection for failover which is expensive in nature as required additional nodes.

3. Effect of the nodes scalability has neglected in the majority of the existing research

4. There is no technique to replace the failure node with existing nodes.

\section{CONCLUSION}

Fault tolerance is a key research study in the Mobile Ad Hoc Networks. This review paper shown a review of various fault tolerance algorithms and protocols designed for MANETs. From this survey paper, the examiners can find what type of failures occur and the various techniques and protocols to handle problems like node failure, link failure, network failure, transmission power, energy etc. The survey protocols and algorithms presented here can enhanced the performance overall performance with regards to reliability, throughput, and life time. Challenges helps researcher to boost the constraint for effective as well as efficient fault tolerant protocol.

\section{REFERENCES}

[1] Nancharaiah, B., and B. Chandra Mohan. "The performance of a hybrid routing intelligent algorithm in a mobile ad hoc network." Computers \&Electrical Engineering 40, no. 4, pp. 1255-1264,2014.

[2] Boudries, Abdelmalek, Makhlouf Aliouat, and Patrick Siarry. "Detection and replacement of a failing node in the wireless sensors networks." Computers \& Electrical Engineering 40, no. 2 pp. 421-432, 2014.

[3] Misra, Sudip, Sanjay Kumar Dhurandher, Mohammad S. Obaidat, Karan Verma, and Pushkar Gupta. "Using antlike agents for fault-tolerant routing in mobile ad-hoc networks."In Communications, 2009. ICC'09. IEEE International Conference on, pp. 1-5. IEEE, 2009.

[4] Li, Jie, Erling Gong, Zhiqiang Sun, Long Li, and Hongwei Xie. "Fault-tolerant topology control in aeronautical ad hoc networks." In Mechatronics and Automation (ICMA), 2014 IEEE International Conference on, pp. 368-372. IEEE, 2014.

[5] Lauf, Adrian P., and William H. Robinson. "Fault tolerance in MANETs using a task-to-resource reallocation framework." In Computational Science and Engineering, 2009. CSE'09. International Conference on, vol. 2, pp. 753-758. IEEE, 2009

[6] Gupta, Anuj K., Harsh Sadawarti, and Anil K. Verma. "MANET routing protocols based on Ant Colony Optimization." International Journal of Modeling and Optimization 2, no. 1 ,pp.42-49.,2012.

[7] Junhai, Luo, Ye Danxia, Xue Liu, and Fan Mingyu. "A survey of multicast routing protocols for mobile ad-hoc networks." Communications Surveys \& Tutorials, IEEE 11, no. 1 (2009): 78-91.

[8] Vijayakumar, P., and T. Poongkuzhali. "Efficient power aware broadcasting technique for mobile ad hoc network." Procedia Engineering 30 (2012): 782-789.
[9] V. Jayalakshmi, Dr. R. Rameshkumar ."MULTIPATH FAULT TOLERANT ROUTING PROTOCOL IN MANET"International Journal on AdHoc Networking Systems (IJANS) Vol. 2, No. 1, January 2012.

[10] Kumar, A., S. S. Srivastava, B. Ram, and P. Singh. "Exploring a new dimension in MANETs through a new routing protocol." In Electronics Computer Technology (ICECT), 2011 3rd International Conference on, vol. 5, pp. 328-331. IEEE, 2011.

[11] Melamed, Roie, Idit Keidar, and Yoav Barel. "Octopus: A fault-tolerant and efficient ad-hoc routing protocol." Wireless Networks 14, no. 6 ,pp: 777 793.,2008.

[12] Aggarwal, Parul. "A study on achieving fault tolerance in MANETs." Journal of Global Research in Computer Science 4, no. 12 ,pp: 42-47. ,2014.

[13] Jain, Rohit, Abhinav Mehta, and Vinay Somani. "Performance Evaluation of Fault Tolerance Protocols in MANET." International Journal of Computer Applications 61, no. 2 (2013).

[14] Ahmed, RanaEjaz. "A Fault-Tolerant Routing Protocol for Mobile Ad Hoc Networks." Journal of Advances in Information Technology 2, no. 2 ,pp: 128-132.2011.

[15] Huang, C., and Shou-Chih Lo. "A comprehensive survey of multicast routing protocols for mobile ad hoc networks." Journal of Internet Technology 9, no. 1 (2008): 25-34.

[16] Waqas A. Imtiaz, M. Afaq, M. Faheem "TCP and UDP Based Comparison of MANET Routing Protocols Using OPNET"

[17] Sakib, Kazi, Zahir Tari, and Peter Bertok. "Failed node replacement policies for maximising sensor network lifetime." In Wireless and Pervasive Computing (ISWPC), 2011 6th International Symposium on, pp. 1-6. IEEE, 2011

[18] Banwari, Deepanshu Sharma, and Deepak Upadhyay. "Routing Algorithm for MANET: A comparative study." Pp: 193-197.2013.

[19] Hinds, Alex, Michael Ngulube, Shaoying Zhu, and Hussain Al-Aqrabi. "A Review of Routing Protocols for Mobile Ad-Hoc NETworks (MANET)." International Journal of Information and Education Technology 3, no. 1 (2013).

[20] Gupta, Anuj K., Harsh Sadawarti, and Anil K. Verma. "Review of various Routing Protocols for MANETs." proceedings of International Journal of Information and Electronics Engineering 1, no. 3 (2011)

[21] Mohapatra, S., and P. Kanungo. "Performance analysis of AODV, DSR, OLSR and DSDV routing protocols using NS2 Simulator." Procedia Engineering 30 (2012): 69-76.

[22] Ghosekar, Pravin, Girish Katkar, and Pradip Ghorpade. "Mobile ad hoc networking: imperatives and challenges." IJCA Special Issue on MANETs 3 (2010): 153-158.

[23] Singh, Jagtar, and Natasha Dhiman. "A Review Paper on Introduction to Mobile Ad Hoc Networks." International Journal of Latest Trends in Engineering and Technology (IJLTET) 2, no. 4 (2013). 
[24] Elhadef, Mourad, Azzedine Boukerche, and Hisham Elkadiki. "A distributed fault identification protocol for wireless and mobile ad hoc networks." Journal of Parallel and Distributed Computing 68, no. 3 (2008): 321-335.

[25] Jayalakshmi, V., and Dr Rameshkumar. "R," Multipath Fault Tolerant Routing Protocol in MANET". International Journal of Adhoc Networkig Systems 2, no. 1 (2012)

[26] Nazeeruddin, M., G. Parr, and B. Scotney. "Faulttolerant dynamic host auto-configuration protocol for heterogeneous MANETs." Proc. of 14th IST Mobile \& Wireless Summit, Dresden, Germany (2005): 19-23.

[27] Aggarwal, Parul. "A study on achieving fault tolerance in MANETs." Journal of Global Research in Computer Science 4, no. 12 (2014): 42-47.

[28] Ahmed, Rana Ejaz. "A Fault-Tolerant Routing Protocol for Mobile Ad Hoc Networks." Journal of Advances in Information Technology 2, no. 2 (2011): 128-132.

[29] Melamed, Roie, Idit Keidar, and Yoav Barel. "Octopus: A fault-tolerant and efficient ad-hoc routing protocol." Wireless Networks 14, no. 6 (2008): 777-793

[30] Holland, Gavin, and Nitin Vaidya. "Analysis of TCP performance over mobile ad hoc networks." Wireless Networks 8, no. 2/3 (2002): 275-288

[31] Gupta, Anuj K., Harsh Sadawarti, and Anil K. Verma. "MANET routing protocols based on Ant Colony Optimization." International Journal of Modeling and Optimization 2, no. 1 (2012): 42-49.
[32] Garg, Dweepna, and Parth Gohil. "ANT COLONY OPTIMIZED ROUTING FOR MOBILE ADHOC NETWORKS (MANET)."

[33] Arun Kumar B. R. , Lokanatha C. Reddy, Prakash S. Hiremath "MOBILE AD HOC NETWORKS: ISSUES, RESEARCH TRENDS AND EXPERIMENTS".

[34] Adeluyi, Olufemi, and Jeong-A. Lee. "SMiRA: A bioinspired fault tolerant routing algorithm for MANETs." In ICT Convergence (ICTC), 2012 International Conference on, pp. 78-84. IEEE, 2012.

[35] Khazaei, K., S. Mohammadi, and A. Momeni. "A fault tolerant location management for MNANET." In Wireless and Microwave Technology Conference, 2009. WAMICON'09. IEEE 10th Annual, pp. 1-6. IEEE, 2009.

[36] Kiran, K., P. Deepa Shenoy, K. R. Venugopal, and Lalit M. Patnaik. "Fault tolerant BeeHive routing in mobile ad-hoc multi-radio network." In Region 10 Symposium, 2014 IEEE, pp. 116-120. IEEE, 2014

[37] Li, Wanlong, Dayou Liu, and Hui Zhao. "FaultTolerance Mechanism of Mobile Agent In Mobile Ad Hoc Networks." In Wireless Communications, Networking and Mobile Computing, 2008. WiCOM'08. 4th International Conference on, pp. 1-4. IEEE, 2008.

[38] Oommen, B. John, and Sudip Misra. "A fault-tolerant routing algorithmfor mobile ad hoc networks using a stochastic learning-based weak estimation procedure." In Wireless and Mobile Computing, Networking and Communications, 2006.(WiMob'2006). IEEE International Conference on, pp. 31-37. IEEE, 2006 